\title{
Validation of Eduda Applications and Self Resilience
}

\author{
Raudah Zaimah Dalimunthe ${ }^{1}$, Rosmala Dewi ${ }^{2 *}$, Martiano $^{3}$, \\ Muhammad Bukhori Dalimunthe ${ }^{4}$ \\ 1)Universitas Sutan Ageng Tirtayasa, Indonesia \\ 2,3,4)Universitas Negeri Medan, Indonesia \\ *ros_dw@unimed.ac.id
}

\begin{abstract}
Curiosity about drugs is obtained from friends using mobile phones, wanting to try drugs, curious, trends, and to be accepted by the group. The research purpose is to develop a smartphone application-based educational service program which is also called Education of Drug Adversity (Eduda). Research locations in SMAN 14 and SMAN 1 Kabanjahe, research subjects students have low self resilience totaling 80 student. Action research design, and data collection using questionnaires, in-depth interviews, and observation. Initial measurement results at SMAN 14 Medan and SMAN 1 Kabanjahe that there are students who have low self resilience, who are clients. His parents were invited to attend the Eduda program at school. While students who have high self resilience become peer counselors, who will be trained using the Eduda program. The results of the study at SMAN 14 initial conditions of endurance average of $61.48 \%$ which is classified as low category. Cycle II in the medium category, and Cycle III in the high category. Whereas in SMAN 1 Kabanjahe the initial condition of $60.75 \%$ was in the low category. Cycle II in the medium category, and Cycle III in the high category. This shows the Eduda program can increase students' self resilience to drugs. The Eduda program offers a solution so that teenagers can consult their closest people, namely trained peer counselors, counseling guidance teachers, and parents by utilizing the facilities contained in the Eduda program.
\end{abstract}

Keywords: eduda, self resilience.

\section{Introduction}

The most serious threat to the development process of adolescents today, things that affect the adaptive process of facing challenges, life pressures. Masten [1] said adolescent confusion results in the cognitive development, emotional regulation and behavior, in supportive relationships with adults. The adaptive process of facing challenger and difficulties in this study is called self resilience.

Damayanti [2] explained the Indonesian Child Protection Commission noted of the 87 million child population in Indonesia, as many as 5.9 million became drug addict with a maximum age of 18 years. They become addicted to narcotics because of influenced by closest to them. Furthermore, the National Narcotics Agency shows that drug users in Indonesia reached 5.1 million people, and it was the largest is in Asia. Of that amount, 40\% came from students and college student. This data is a sign of low adolescent self-resilience [3].

Research on risk of self-resilience began from studied of children who live in disadvantaged or dangerous situations, noted that people who have the ability to cope with 
various types of risk factors, a series of conditions and critical incidents, are possibility to increase someone solve the problem [4].

Bronfenbrenner $[5,[6]$ said human development through time and interaction in complex contexts. Children who are developing many things are interrelated in the micro system such as family, school, peer group, environment, and macro system from a wider social context.

Resilience understanding has a dichotomy between individual work and system work. Factors in individuals were built by the system in the family, school, social environment of friendship in the community. Resilience was built by risk factors and protective factors that was owned by individuals at all levels around them. Risk factors are factors that make a person face more difficult. A person did not make a problem by themselves but influence form social environment. Protective factors are factors that act to protect individuals from developing problems even in the face of difficulties and risk factors.

Resilience is more relative and dynamic than the processes that occur over time involved in overcoming difficulties. Resilience depends on the number, type, and level of risk that a person faces difficulties. Masten [1] said resilience is characterized by good outcomes despite serious threats to adaption or development.

Based on research results adolescents found in outside schools, inside schools, and in youth rehabilitation center were built on 6 latent variables are technology utilization, awareness of the dangers of drugs, life skills, spiritual guidance, self-potential [7]. Off all the subject studied, adolescents whose drug initiation and habituation have below average and average intelligence, having a low internal locus of control means that the adolescents believes that their life and future depend on others. All subjects said utilization of smart phone technology was used to recognize and obtain drugs. Self resilience of adolescent drug initiation is in higher schools than teenagers outside of school and rehabilitation center. Adolescent life skills in a low group specifically indicators of altruism and responsible citizenship. Information technology influences drug awareness education, spiritual guidance influences self resilience initiating drugs. Effectiveness of technology utilization affects life skills and spiritual guidance. Whereas awareness drug education, and life skills were not effect to self resilience. Of all variables are measured by children outside school self resilience is a lowest score variable. therefore to build self resilience starts form spiritual guidance by utilizing information technology. From the result of the study research team build education using android technology, or eduda application (Education of Drug Adversity)

Research result Dewi [7] that; 1) techonology utilization has no effect on self potential was measured by the level of intelligence and Locus of control; 2) technology utilization has effect on awareness the dangers of drugs, life skills, and spiritual guidance; 3) awareness of the drugs danger, life skills, and spiritual guidance has an effect self resilience drug initiation; 4) self-potential has no effect to self-resilience initiating drugs. On the basis of the results study an eduda application was compiled ad an android based, consisting of 4 parts are client eduda, peer educator eduda, parents eduda, and teacher counseling education eduda. Eduda application was implemented and reported by the guidance counseling teacher as proof of performance each semester. Client eduda is a place for students who have studied problems, career, personal, and social.

Its application to students' smartphone used ass a learning tool with the following steps: 1) The application was uploaded in play store; 2) installed; 3 ) registration; and 4) ready for use according to needs by choosing and existing menu, if you want to learn to increase selfresilience see the menu fot students, select the student menu. If parents want to learn to be an educator, click the parent menu, if the counseling guidance teacher wants to carry out the guidance service click the counseling teacher guidance menu. 
Education is a social environment that direcly plays a role to increasing individual selfresilience. Because self-resilience is not a personality that can not be changed [8]. Communicating the importance of self-resilience to others, with special emphasis on their potential role as a protective factor in childrens' lives are parents and teachers. Protection leads to resilience influenced by context and because the process of building self-resilience tends to be contextually specific. Therefore the role of educators around students are parents, teacher, peers needs to get enlightened efforts to improve self-resilience in this study the team designed an application called eduda.

Resilience is something that can be learned school is one place that can facilitate the development of one's resilience [9]. In the context of schools, the level of academic resilience is mutually influential with 3 factors related to psychology and education are (1) pleasure or enjoy the school, (2) participation in class, (3) self-esteem [10].

The bio-ecological development model is represented by two dimensions: on relating to the biological attributes of the child the other related to the contextual variables that surround the child [11]. School and school experience are very important to increase resilience. Many studies have found that children's school experiences and relationships they have a significant protective effect [12]. The concepts of resilience with emphasis on increasing environmental protection factors. If related to the role Indonesian schools promoting social competence and welfare of children in the school environment. School improve social competence that is why teachers actively develop a good relationship, encourage participation, and provide clear boundaries, rules and hopes.

Resilience was seen as an interactive model that takes on three levels: individual anda family level, at school level, and at local authority level. At each level, they did five core functions: assessment, intervention, consultation, research, and practice. Based on the interactive model, the team developed the eduda application model.

Resilience is a dynamic concept looking at the quality of individual adaptation as a result of interactive processes between factors operating at the individual, family, school, and community level. Luthar et al., [13] define resilience as a dynamic process that includes positive adaptation in the context of significant difficulties.

There are two aspects that determine resilience: 1) exposure the significant threats or difficulties: 2) evidence of achieving positive adaption despite threats to the development process [8]. Resilience is ability of humans adaption to deal with tragedies, trauma, difficulties, and significant stressors. Wales's resilience model refers to construction approach, resilience as a result of negotiation between individuals and their environment to determine their good resources in the midst conditions that are collectively seen as detrimental [14]. Following this definition, the resources available to individuals will determine how they are and whether they are able to express their resilience. To help the research and development of resilience theory as an ecologically dependent social concepts. Ungar [15] proposes four resilience principles: decentralization, complexity, disorder, and cultural relativity. Combined all provide a framework to explain resilience. Decentralization means resilience has an individual characteristic and processes its environment in accordance with care. Complexity means that processes that promote resilience produce predictable results. In fact, possibility has a good result depends on threat level by changing environment. Irregularity means, even though the environment offers protective children's experience of social justice, it was not necessary to follow that environment is more directly contributing to vulnerability. Cultural relativity means the multilingual community and the process of language acquisition, culture as a productive force for psychosocial health is important to contribute to the resilience process. Culture referred to daily practice through individuals and group manifests a set of 
shared values, beliefs, language and habits. To cherish resilience as complex construction of diverse results, competing claims of truth from cultures that cross each other in Indonesia children's lives must be accounted for. Depending on the social location were resilience is measured, the results can reflect the unique of local culture. The better match between child and child's expectations are culturally restricted, the greater child is considered tough.

The process of resilience depends on input from children and their ecology as stated in such strengths can be used to facilitate resilience with all children including orphans. Facilitation to recognize children's potential, take action and support, one way is invite children to participate and given them a chance to build their ecology resilience together. The same opinion [16] said, our act must be shared with the ecological children to build their resilience, not making children passive in the resilience increase transaction also expressed.

\section{Research Method}

The study was conducted at Senior High School 14 Medan and Senior High School 1 Kabanjahe. Class X determination was obtained based on initial interviews and recommendations from the counseling guidance teacher that having low self-resilience. The data collection instrument used a self-resilience questionnaire consisting of science and social class students. The questionnaire has two properties are Favorouable positif and Unfavorouable negatif. Each statement item has 3 alternative answers is 'Yes, sometimes, no'. Statements that favorable are given a range of 3,2,1 and unfavorable ones are given a range of $1,2,3$.

Self-resilience focused consist of: (1) commitment; (2) self-control; and (3) able to face challenges. Design an action research conducting by two cycles. Each cycles consists of four components of action research, that is: (1) planning; (2) implementation; (3) observation; (4) reflection [17].

At the planning stage: (1) arrange a research permit with the school principal; (2) making a schedule of activities, and arranging the place of activity implementation, Identifying parties who are service participant; (3) identification of student who less good self-resilience by using a questionnaire; (4) prepared learning materials for self-resilience counseling that would be presented in the form videos of problem solving skills, decision making, critical thinking, parenting, collaboration between parents and teacher for improving student self-resilience; (5) compile questionnaire instruments, observation sheets, work sheets and notes to observe the research implementation.

At the implementation level study began with the trial instrument. The validity test of the resilience instrument was carried out at senior high school 14 Medan with 30 student respondents obtained 33 valid items and 17 invalid items. Reliability test using the Alpha formula, obtained a value of 0,82 . Video observation sheet contains characteristics according to: 1) message clearly; 2) friendly with users; 3) able to represent content; 4) multimedia; 5) high resolution; and: 6) can be used classically and individually. Responses of counseling guidance teachers, parents, and students to the eduda application, states this application is very important and all schools must have it. Headmaster agreed that students would bring a smart phone while the application trial was taking place. Furthermore eduda application used after school hours are over. After school hours were over, the students are welcome to used counseling services via eduda application.

Observation did during the action. Observers (research team) used observation instruments, there were an observation sheets completed with field notes. Observation phase 
was an observation activity on the results or impact of counselee action (students). Observation were made during the process of watching a video.

Reflection was done by analyzing, reviewing, and predicting by process has been done. This activity intend to evaluate the weaknesses of the implementation first cycle, as well as correcting material to improve the second cycle implementation.

\section{Results and Discussion}

Eduda application was equipped with learning media for students about self resistance to drugs which the video provides innovative learning for students. Eduda Application was based on a structured communication algorithm where students will communicate with the guidance counseling teacher, convey, explain the problem with the principle of confidentiality. Because of this the teacher has more access to learn about student's development, problems and constrains.

Furthermore, students could consult with their peers. Communication between them can be known and controlled by the counseling guidance teacher so the guidance process runs properly.

Students could also communicate with parents, so their parents know child's development. Parents could coordinate with the counseling teacher so the forming close relationships between parents, teachers, friends, and all students. A close relationship around student life was important to build self-resilience.

Individual and family factors are consistent to build self-resilience by Luthar et al., [18] including (a) important contexts of children's lives, dependent on their caregivers, high rates of maternal depression and pressures of domestic life in Indonesia, (b) individual characteristic like; temperament and cognitive ability relative stability, and (c) other asset development contributions (impact on self-regulation and children's coping skills). Same as resilience has been defined as the maintenance of successful and healthy functions or adaptations in the context of significant difficulties or threats [19].

Early phase of used eduda application, the counseling guidance teacher must coordinate with parents, students, and student counselors. Counseling guidance teacher must explained the purpose of using the application to students' parents, and Eduda application could downloaded via google play or caption eduda. Furthermore, parents must used the application to monitor their child's development. Counseling guidance teacher must give a chance for students to fill out self-resilience questionnaires through the Google form in ordered to get students who have high self-resilience to be students of peer counselors. Counseling guidance teacher can monitor and make conversation directly also follow the results or peer counseling if students have experience serious problems.

Students who become peer counselors have an application that can be downloaded via google play, the peer counselor was equipped with a chat application to students, and learning videos how to become friends who educate their friends to be better students who need helped. Peer counselor students could act as students and asked the problem to other educators, counseling teachers, or their friends also.

Communication process used the eduda application made by students of SMAN 14 Medan and SMAN 11 Kabanjahe in the first cycle was very enthusiastic, students tended to express more problems about love, where the problem was addressed to their peer counselors, then they responded positively. Data conversations that was made, can be seen and printed by the counseling teacher as a report on the development of students. Counseling guidance has 
full control of application running, they could add students, parents, and their peer counselors. Through the procedures in each school.

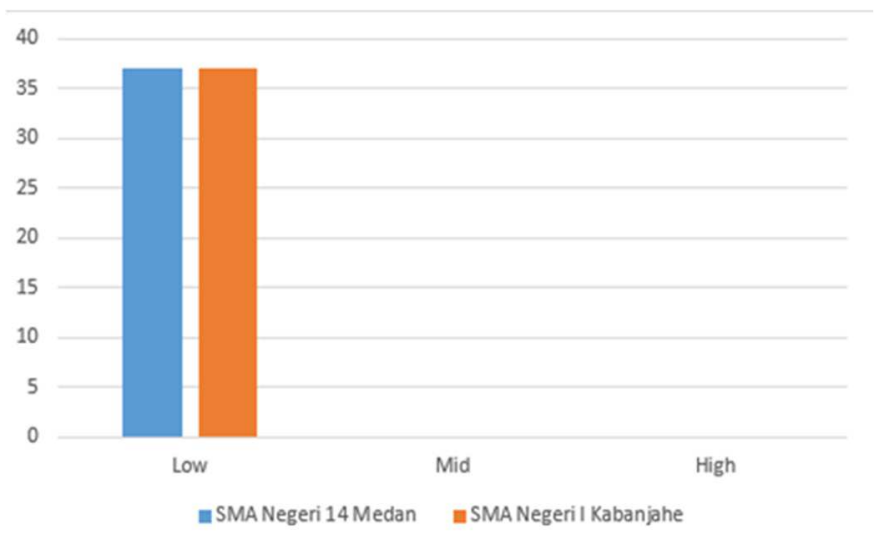

Figure 1. Initial data tested

Students self resilience data contained in two school have 37 students weak self resilience, so the research did on students to test the variables studied. This research continued in first cycle and conducted training for students, counseling guidance teachers, and parents in conducted the counseling guidance process by using the eduda application. Recapitulaion of results obtained in cylces II and III can be seen in graph below:

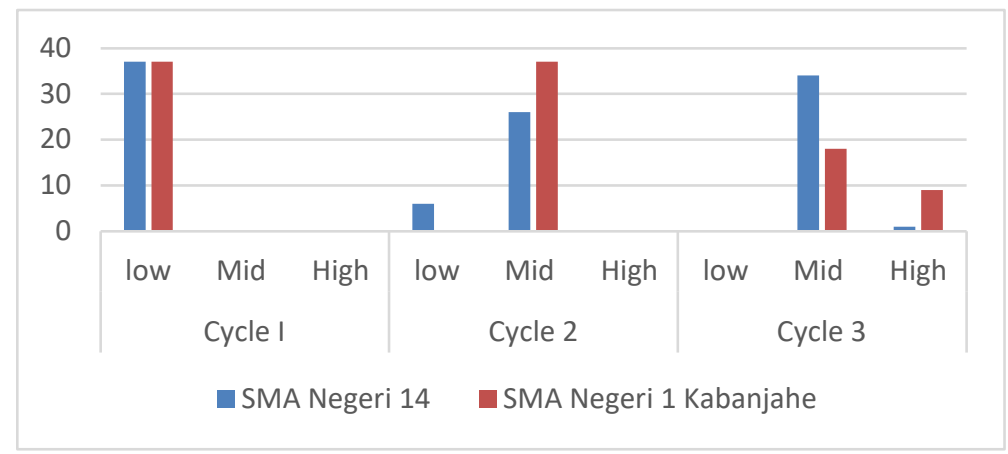

Figure 2. Self Resilience in the initial data cycle I, cycle II, and III

The result of cycle II at SMAN 14 Medan there were 6 students to the weak category selfresilience, 26 students in the medium category, while at SMAN 1 Kabanjahe there were 37 in the medium category, from this data the self-resilience was increase from observation of initial data but there were students who have weak self-resilience.

Cycle III, the results obtained at SMAN 14 Medan have 34 students belonging to the medium category and 1 person who has a high category, meanwhile at SMAN 1 Kabanjahe has 18 people of the medium category and 9 people in the high category. The result showed that education is a social environment that directly plays a role in increasing individual resilience. Because resilience was not a personality that cannot be changed [8]. Based on observation result in this studied the enthusiasm of using eduda application was effective and provides improved based on data below. 


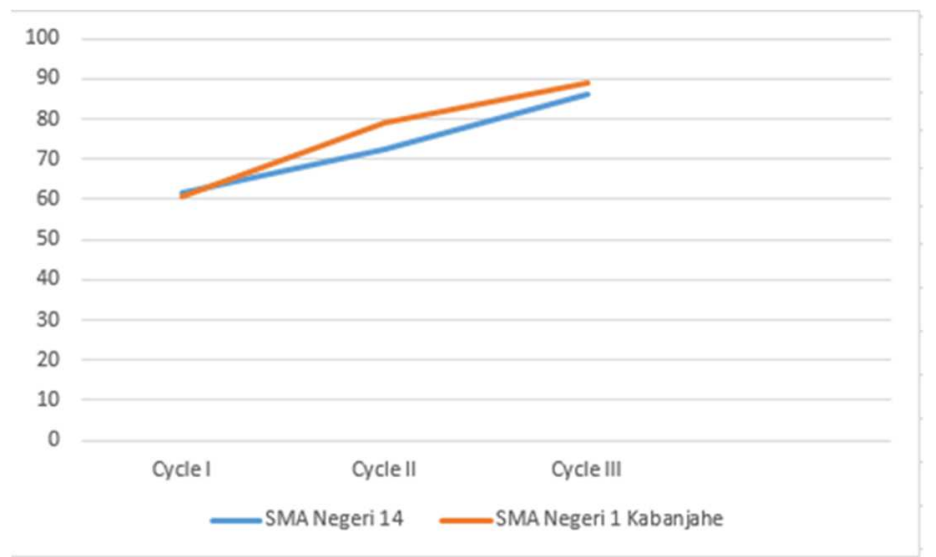

Figure 3. Increased Self Resilience

From the preliminary data found in SMAN 14, it has an average of $61.48 \%$ which belongs to the weak category, in cycle II it is $72.25 \%$ which is classified in the medium category, and in cycle III it is $85.97 \%$ classified in the high category. In the context of significant exposure to difficulties at school, resilience is both an individual's capacity to navigate the path to the psychological, social, cultural and physical resources that sustain them, and their individual and collective capacity to negotiate for these resources is provided and experienced culture meaningful way [15]. The results of SMAN 1 Kabanjahe testing the initial data of $60.75 \%$ of students classified in the weak category, in cycle II of $78.89 \%$ of students in the medium category, and in cycle III of $89.08 \%$ of students classified in the high category. Strength of character is forgiveness, compassion, humility, caution, and self-control [8]. The strength of this character seems to be a key factor aiming to foster to promote resilience. Building character through eduda applications helps students, parents and teachers build student selfresilience, because all parties act as educators in schools

\section{Conclusion}

Based on the test results, some conclusions and suggestions are made as follows: (1) the resilience process depends on the input of children and their ecology; (2) resilience is more relative and dynamic, the process of occurrence from time to time is involved in overcoming difficulties; (3) resilience is the quality of individual adaptation as a result of an interactive process between factors operating in individuals, families, schools, and communities; (4) building character through eduda applications helps students face difficulties can improve selfresilience; (5) the involvement of friends, parents, teachers in the process of interaction in the face of difficulties building student self-resilience; (6) it is recommended that all parties around student life should be educators for the environment; (7) learning to become an educator can be found in eduda applications; (8) leaders of educational institutions at the provincial, city, sub-district, school, and foundation level can apply the eduda application to build students' self resilience with ease, practicality and fun.

\section{Acknowledgements}

The research team is grateful for the funding provided by the Ministry of Research, Technology and Higher Education, Indonesia. 


\section{References}

[1] Masten, A.S. (2001), Ordinary magic: Resilience processes in development.American Psychologist, 56, pp.227-238.

[2] Damayanti, A.U. (2018), 5,9 Juta Anak Indonesia Jadi Pecandu Narkoba. https://nasional.okezone.com/read/2018/03/06/337/1868702/5-9-juta-anak-indonesiajadi-pecandu-narkoba.

[3] Badan Narkotika Nasional, (2017), 40\% Pengguna Narkoba Pelajar \& Mahasiswa (Koran Sindo) https://nasional.sindonews.com/read/1257498/15/40-pengguna-narkobapelajar-mahasiswa-1510710950, accessed 6 August 2019.

[4] Anthony, E. J. (1974), The Syndrome of The Psychologically Invulnerable Child. In E. J. Anthony, \& C. Koupernik (Eds.), The child in his family: Children at psychiatric risk, pp. 529-545. New York, NY: Wiley.

[5] Bronfenbrenner, U. (1979), The Ecology of Human Ddevelopment: Experiments by Nature and Design. Cambridge, MA: Harvard University Press.

[6] Bronfenbrenner, U. Ecological systems theory. In R. Vasta (Ed.), (1989), Six theories of child evelopment: Revised Formulations and Current Issues (pp. 187-250). Greenwich, CT: JAI Press.

[7] Dewi, R. (2018), Model Membangun Ketahanan Diri terhadap Inisiasi dan Pembiasaan Narkoba Menggukan Aplikasi Edu-da. Laporan Penelitian. Direktorat Jenderal Penguatan Riset dan Pengembangan. Kementerian Riset, Teknologi, dan Pendidikan Tinggi. Universitas Negeri Medan.

[8] Toland, J and Carrigan, D. Educational psychology and resilience: New concept, new opportunities. School Psychology International, 32(1), pp. 95-106.

[9] Reivich, K., and Shatte, A. (2002), The Resilience Factor: 7 Keys To Finding Your Inner Strength And Overcome Life's Hurdles. New York: Broadway Book.

[10] Martin, A.J., \& Marsh, H. W. (2006), Academic Resilience and Its Psychological and Educational.

[11] Schoon, I. Risk and resilience. (2006), Adaptations in changing times. Cambridge: Cambridge University Press.

[12] Werner, E. E., and Smith, R. S. (2001), Journeys from Childhood to Mid-life: Risk, Resilience and Recovery. Ithaca, NY: Cornell University Press.

[13] Luthar, S. S., Gicchetti, D., and Becker, B. (2000), The construct of resilience: A critical evaluation and guidelines for future work. Child Development, 71; pp. 543-562.

[14] Ungar, M.A. (2004), Constructionist Discourse on Resilience: Multiple Contexts, Multiple Realities Among At-Risk Children and Youth.Youth \& Society, 35; pp. 341-365.

[15] Ungar, M.A. (2008), Resilience across cultures. British Journal of Social Work, 38; pp. $218-235$.

[16] Theron, L.C and Donald, D.R. (2015), School Psychology International. Chinese Univeristy of Hong Kong on February 8, 34(1); pp. 51-66. 
[17] Kemmis S. and Mc Taggart. (1988), The Action Research Planner $3^{\text {rd }}$. Victoria: Deakin University.

[18] Luthar, S. S., Sawyer, J. A., and Brown, P. J. (2006), Conceptual issues in the studies of resilience-Past, present, and future research. Annals of the New York Academy of Sciences, 1095; pp. 105-115.

[19] Masten, A. S., and Obradovic, J. (2006), Competence and resilience in development. Annals of the New York Academy of Sciences, 1094; pp. 13-27. 